\title{
EVALUATION OF LAPAROSCOPIC ULTRASOUND AS A ROUTINE METHOD FOR ASSESSMENT OF COMMON BILE DUCT PATENCY IN PATIENT WITH HISTORY OF CALCULAR OBSTRUCTIVE JAUNDICE
} By

AHMED F. ELKASED ${ }^{1}$, AWATEF E. FARGALY ${ }^{1}$, YOUSSEF F. YOUSSEF ${ }^{2}$, MOHAMED ABBAS ${ }^{2^{\star}}$, MOHAMED S. AMAR ${ }^{1}$, M EMAD ESMAT $^{2}$, HESHAM A. ABDELHAMID ${ }^{2}$, HISHAM ABDELAZIZ ${ }^{2}$ and AMR MOSTAFA ${ }^{2}$

Department of General Surgery, Faculty of Medicine ${ }^{1}$, Menoufia University, ShebinEl-Kom, and Department of General Surgery ${ }^{2}$, Theodor Bilharz Research Institute, Imbaba P.O.B. 30. Giza, Egypt ( ${ }^{*}$ Correspondence: mabbas_mahmoud@yahoo.com)

\begin{abstract}
Intraoperative cholangiogram (IOC) is routinely used during cholecystectomy (either open or laparoscopic) in cases of cholelithiasis with history of obstructive jaundice (OJ). It is performed in such cases with no preoperative imaging that confirms the patency of biliary tree and during exploration of common bile duct. Intraoperative ultrasound (IOUS) has recently become a visualizing tool for anatomy and pathology of biliary tree which is safe, faster and less invasive compared to IOC.

This is a prospective controlled randomized trial, conducted on 60 patients undergoing laparoscopic cholecystectomy for cholelithiasis with history of OJ, with no present OJ. It was held in the surgery department in Faculty of Medicine, Menoufia University and Theodor Bilharz Research Institute, from 2014 to 2017. Each patient underwent IOUS then, IOC during laparoscopic cholecystectomy. The study compared between both imaging techniques regarding procedure time, visualization of biliary tree, detection of any common bile duct (CBD) stone, biliary or vascular anomalies, and intra-or postoperative complications in the form of obstructive jaundice or iatrogenic biliary injury.

The results showed a significant difference in time of the procedure with a mean time ( $\mathrm{min})$ of 9.60 \pm 1.224 (3-25) in IOUS and 14.391 $\pm 1.356(5-30)$ in IOC. Mean CBD diameter ( $\mathrm{mm})$ is $5.280 \pm 0.6957(2.8-18)$ in IOUS \& $7.010 \pm 0.7162(3.5-22)$ in IOC without significant differences. IOUS has $100 \%$ sensitivity and $96.7 \%$ specificity while IOC has $100 \%$ sensitivity and $100 \%$ specificity. A case with vascular anomaly and one with duct anomaly were detected by IOUS. The vascular anomaly could not be detected with IOC. There was no post-operative complication in the form of missed CBD stones or bile leakage.
\end{abstract}

Key words: Intraoperative ultrasound, Intraoperative cholangiography, Laparoscopic cholecystectomy, Choledocholithiasis.

\section{Introduction}

Disorders of the biliary tract often manifested with symptoms and signs related to obstruction, including pain, jaundice, pruritus, fever, and abnormal liver biochemical test levels. However, the biliary stone diseases can have a spectrum of presentations, including absence of symptoms, in which case cross-sectional imaging plays an important role in diagnosis. Strictures can also cause obstruction, and, although the majority are concerning for malignancy, a number of benign entities need to be considered, such as the primary sclerosing cholangitis and immunoglobulin G4-related disease (Benias et al, 2018). Most of biliary stones are found in the gallbladder, but they sometimes pass through the cystic duct into extrahepatic and /or intrahepatic bile ducts to become bileduct stones, causing conditions known as choledocholithiasis and hepatolithiasis. Some of gallstone patient's concomitantly suffered from bile-duct stones (Copelan and Kapoor, 2015). The conventional view, supported by randomized trials, is that laparoscopic cholecystectomy the gold standard treatment for gall stones rather than the open surgery. The use of the intraoperative cholangiography (IOC), routinely rather than selectively, during laparoscopic cholecystectomy (LC) is 
controversial. Studies proved that the laparoscopic ultrasound (LUS) to be safe, quick, and effective not only for screening of the bile duct for stones, but also for evaluating the biliary anatomy (Terpstra, 1996). IOC drawback is the consequent lengthening of operative time by about 15 minutes (Machi et al, 2007). But, Laparoscopic ultrasound did not gain popularity because of the learning curve of performing it confidentially and the cost of the apparatus with the probe $(\mathrm{Ca}-$ theline et al, 2002).

The study aimed to evaluate procedure time, visualization of biliary tree, detection of any CBD stone, detection of biliary or vascular anomalies, failure to IOC (failure to cannulate CBD or to obtain clear images) and any intraoperative complications, also, evaluated post-operative complications in form of missed CBD stone or bile leakage.

\section{Patients and Methods}

This is a prospective randomized study conducted on 60 patients with gall bladder stones and history of obstructive with or without jaundice at the operation time (2014 to 2018). All patients were subjected to careful history taking, clinical and laboratory examinations. Each patient had IOUS then IOC during laparoscopic cholecystectomy. Patients with calcular obstructive jaundice and non calcular were excluded.

The study was approved by Ethics Committee of Theodor Bilharz Research Institute. An informed consent was taken from all patients in full details.

Operative technique: Patient was put in supine position and generally anaesthetized. Four ports of conventional laparoscopic cholecystectomy were inserted. Identification of both cystic artery and duct was done and both imaging technique were performed.

Scanning technique of IOUS: This mainly assessed bile ducts patency. Laparoscopic telescope was first introduced in either epigastric or umbilical $10 \mathrm{~mm}$ port to visualize the LUS probe which was introduced into the other port. As a start, the transducer put over segment five to identify gallbladder shadowing stones, sludge or thickening. Proximal biliary tree was firstly assessed via a trans-hepatic view of the confluence of the ducts by placing the probe over segment four of liver and longitudinal view of common hepatic duct just below the liver. A crosssectional cut of right hepatic artery was visualized, which more commonly between the common hepatic duct and portal vein. Third structure was the portal vein. Fourth one was caudate lobe of the liver. Fifth was vena cava. The probe was next placed between liver and anterior surface of hepatoduodenal window to obtain a longitudinal view of the hepatoduodenal ligament structures. The probe was put on the common hepatic duct with a rotating clockwise/counterclockwise motion until bile duct was identified. Duct was confirmed by following it out distally and proximally verifying its normal anatomy and absence of stone acoustic shadow. The presence of a stone was classically detected by posterior acoustic shadowing. The nonvascular nature of the common bile duct was confirmed with Doppler or color Doppler imaging. The triad of CBD laterally, hepatic artery medially and portal vein posteriorly was then detected with a transverse view just above the pancreatic level. With the larger size of portal vein, often called "Mickey Mouse" view since the common bile duct and hepatic artery form the ears and portal vein form the face? The tip of the probe was deflected laterally and downward over the duodenum. CBD was traced from proximal to distal to be easily seen in cross section. At level of ampulla of Vatter, the pancreatic duct was usually joins CBD with an almost $90^{\circ}$ angle. Sometimes, it was difficult to visualize the CBD intra-pancreatic portion because could small and/or compressed. If this is the case, it was necessary to insert a cholangiocatheter inside the cystic duct and inject saline into bile duct. This distended the distal duct and provides a fluid interface to give a better image.

IOC Technique: Surgical clip was applied on cystic duct at the infundibulo-ductal junc- 
tion. A small cut was made in the cystic duct not far from the clip by laparoscopic microscissors. Cystic duct was dilated by the tip of Maryland, then cannulated using a front tipped, saline flushed, size 5 ureteric catheter introduced through a cholangioclamp introduced via epigastric $10 \mathrm{~mm}$ port and the blades hug the cannulated cystic duct to prevent leakage. Patient was then turned back to neutral position and slightly tilted $\left(15-20^{\circ}\right)$ to the right side to get the vertebral column out of the x-ray field. Urograffin $1 \mathrm{ml}$ diluted with $10 \mathrm{ml}$ normal saline in a $20 \mathrm{ml}$ syringe connected to the catheter free end and injected under fluoroscopic guidance. The images were taken by a C-arm to assess the patency of whole biliary system in both intrahepatic part up to $2^{\text {nd }}$ order divisions and extrahepatic part down to the free dye filling into duodenum (Flum et al, 2003).

Intraoperative treatment of CBD stone: Management of CBD stone was intraoperative diagnosed depended on the number, size and site of the stones and the caliber of the CBD. The detected CBD stones were extracted laparoscopically via a choledocotomy with the aid of Fogarty catheter. Patency was then checked by LUS and intra operative T-tube cholangiography.

\section{Results}

All patients underwent laparoscopic cholecystectomy with IOUS \& IOC. Operative time, IOUS timing was the time immediately started after identification of cystic duct and artery till the start of IOC, ranged from 3 to 25 minutes $(9.60 \pm 1.224)$. But, the IOC timing was the time after IOUS till clipping of cystic duct proximal part, ranged from 5 to 30 minutes (14.391 \pm 1.356$)$.

CBD diameter: With IOUS, CBD diameter ranged from 2.8 to $18 \mathrm{~mm}(5.280 \pm 0.6957)$. With IOC, the CBD diameter ranged from 3.5 to $22 \mathrm{~mm}(7.010 \pm 0.7162)$.

As to adequate visualization of biliary tree, proximal $2 / 3$ of CBD was visualized with IOUS in all cases, while the distal $1 / 3$ was visualized in 48 cases $(80 \%)$ and 60 cases after trans-cystic injection of saline (100\%).
The proximal $2 / 3$ of CBD was visualized by IOC in 60 cases (100\%) and the distal $1 / 3$ of CBD was visualized by IOC in all cases.

The CBD stone by IOUS diagnosed 58 true negative cases and 2 true positive cases. One was $8 \mathrm{~mm}$ CBD stone and second was $15 \mathrm{~mm}$, without false negative cases. One false positive case was diagnosed as having CBD stone by IOUS and not by IOC, \& managed by postoperative magnetic resonance cholangiopancreatography (MRCP), which was negative for CBD stone (sensitivity $100 \%$ \& specificity $98.3 \%$ ). In IOC, the true negative was 58 cases, and true positive 2 cases. There was neither false negative case nor false positives case (sensitivity 100\% \& specificity $100 \%$ ). As to anatomical anomalies, a vascular anomaly was detected only by IOUS in one case in form of Caterpillar right hepatic artery (passing anterior to common hepatic duct), another anomaly of a long low inserted cystic duct detected by both IOUS and IOC. As to intraoperative complications, it was none with using IOUS.

But, with IOC, bile leakage happened in all cases from cystic duct during cannulation without consequences. There were no postoperative complications in form of missed CBD stone or bile leakage.

\section{Discussion}

Diagnosis of CBD stones may be neglectted prior to laparoscopic cholecystectomy and cause complications, such as acute cholangitis or pancreatitis. Patients with verified presence or high-suspicion of CBD stones must undergo endoscopic retrograde cholangio-pancreatography (ERCP) for diagnosis and treatment before receiving laparoscopic cholecystectomy (Perry et al, 2010). But, ERCP is an invasive procedure with certain complication risks and may be inappropriate for most patients with low or medium suspicion. Patients with history of OJ without the hyperbilirubinemia, wide CBD> $10 \mathrm{~mm}$, high alkaline phosphatase, high GGT or risky stones (multiple, smaller than $5 \mathrm{~mm}$ ), have the risk of occult CBD stones. Thus, it was agreeable that a noninvasive procedure with 
a high diagnostic rate should be appropriate for them (Cohen et al, 2002). Pancreatitis in patients with gall stones was a risk for silent CBD stone (Ney et al, 2005). The standard preoperative workup for patients presenting with gall stones has reduced the need for IOC. Liver function tests, abdominal ultrasound, combined with clinical exam, and history are diagnostic for CBD stone but, nonspecific and unreliable (Koo and Traverso 1996). MRCP and ERCP are conclusively preoperative diagnostic for CBD stone (Robertson et al, 1996). Both IOC and LUS have their drawbacks. In the case of IOC, It is not repetitive and we should get the diagnosis on spot, in addition to the risk of radiation and anaphylaxis. IOUS, however, is repetitive, safe, fast as well as ability to diagnose stage malignant OJ and take an US guided biopsy (Champault et al, 1996).

Cholangiography perfectly delineates both anatomy and pathology of biliary tree (Flum et al 2003). However, its preventive effect against bile duct injury is still controversial (Amott, 2005). Cholangiography has the limitation of cystic duct cannulation due to its prominent valve. Besides, the problem that the bile duct injury cannot be prevented in patients with acute cholecystitis or with accessory bile duct in whom the cystic duct can merge into. IOUS, however, does not require new X-ray apparatus, radiologists, or laboratory technician. Two randomized control trials visualized biliary tract anatomy and diagnosis of IOUS for bile duct stones proved better than those for cholangiography (Tranter and Thompson 2003). Falcone et al. (1999) reported that in IOUS, it was necessary to learn procedure from at least 10 cases. While there are many reports on the efficacy of IOUS, but without analysis on the clinical outcome and time burden in the learning curve periods needed for IOUS.

The present results showed that IOUS was comparable to IOC in this respect, and their combination, gave $100 \%$ accuracy and at the same time led to successful intraoperative stone extraction. Special training for IOUS is a must, preferably supervised by someone experienced in both conventional and laparoscopic intraoperative ultrasonography. There is a definite learning curve phenomenon, which explained false positive case at the beginning. The necessary reconstruction of ultrasound images by surgeons' brain is acquired in the training period. Time taken to adequately evaluate biliary tree progressively declined during the course of the experience. A trained operator could perform a full biliary IOUS in less than $5 \mathrm{~min}$. The adequate visualization of the distal CBD was not easy, especially in the obese, but was achieved by intracystic injection of the saline. In the present study, $80 \%$ of the cases were preceded by saline injection and $100 \%$ after injection.

In the present study, the success rate was $100 \%$ in IOUS and $100 \%$ in IOC while the timing ( $\min )$ was 9.7 in IOUS and 14.4 in IOC. Birth et al. (1998) reported a success rate of $>99 \%$ in IOUS and $92 \%$ in IOC and the timing was $7 \mathrm{~min}$ in IOUS \& $16 \mathrm{~min}$ in IOC. Catheline et al. (2002) reported success rate of $100 \%$ in IOUS \& $85 \%$ in IOC and timing was $10 \mathrm{~min}$ in IOUS and $18 \mathrm{~min}$ in IOC. Machi et al. (2009) reported success rate of $95 \%$ in IOUS \& $92 \%$ in IOC and timing was $9.6 \mathrm{~min}$ in IOUS and $16 \mathrm{~min}$ in IOC.

In the present study, the sensitivity was $100 \%$ in both IOUS and IOC and specificity was $98.3 \%$ in IOUS and $100 \%$ in IOC. Thompson et al. (1998) reported sensitivity of $90 \%$ in IOUS \& $98 \%$ in IOC and specificity of $100 \%$ in IOUS \& $98 \%$ in IOC. Siperstein et al. (1999) reported sensitivity of $96 \%$ in IOUS \& $96 \%$ in IOC and specificity of $100 \%$ in IOUS \& $100 \%$ in IOC. Birth et al. (1999) reported sensitivity of $83 \%$ in IOUS \& $100 \%$ in IOC and specificity was $100 \%$ in IOUS \& $99 \%$ in IOC. Catheline et al. (2002) reported sensitivity of $80 \%$ in IOUS \& $75 \%$ in IOC and specificity of $99 \%$ in IOUS \& $99 \%$ in IOC. Tranter et al. (2003) reported sensitivity of $96 \%$ in IOUS \& $86 \%$ in IOC and specificity of $100 \%$ in IOUS \& $99 \%$ in IOC. Machi et al. 
(2009) reported sensitivity of $89 \%$ in IOUS $\& 88 \%$ in IOC and specificity was $100 \%$ in IOUS \& $98 \%$ in IOC.

In the present study, mean CBD diameter was $5.2 \mathrm{~mm}$ in IOUS and $7.0 \mathrm{~mm}$ in IOC. Mean caliber of CBD as measured at IOC was greater than that given by IOUS. This agreed with Catheline et al. (2002) found that the mean CBD diameter was $5.5 \mathrm{~mm}$ in IOUS and $7 \mathrm{~mm}$ in IOC. The overall cost of IOUS assessment of the biliary tree needed to be calculated and that the same multi-function equipment can also be used for staging of gastro-intestinal tumors and percutaneous ultrasound studies (Ney et al, 2005).

Besides, Dili and Bertrand (2017) reported that although inflammatory disease hampers accuracy, the LUS was still advantageous compared to IOC in patients with obscured anatomy. LUS can be performed before any dissection and repeated at will to guide the surgeon especially when hilar mapping is difficult due to fibrosis and inflammation. In two studies LUS prevented conversion in $91 \%$ of patients with difficult scenarios.

Generally speaking, parasitic infections of the biliary tract are a common cause of biliary obstruction in tropical countries leading to such serious complications as cholangitis and cholangiocarcinoma. Ascaris lumbricoides which normally reside in jejunum are actively motile and invade the papilla, thus migrating into the bile duct and causing biliary obstruction. This nematode worm is endemic in rural Egypt particularly among school children (Dyab et al, 2016) Endoscopic retrograde cholangiopancreatography is a useful diagnostic tool with potential for therapeutic management of biliary ascariasis. Fascioliasis, caused by $F$. hepatica and $F$. gigantica, is a zoonotic helminthiasis endemic in Egypt (Haridy et al, 1999) that can present as acute hepatic or chronic biliary tract infection Infection with Clonorchis sinensis a trematode parasite (Morsy and AlMathal, 2011) also reported in Egypt can cause such complications as intrahepatic stones, recurrent pyogenic cholangitis, cirrhos- is, cholelithiasis, pancreatitis, and cholangiocarcinoma. Opisthorchis viverrini, O. felineus (Abdel-Rahim, 2001), zoonotic dicrocoeliasis dendriticum (Massoud et al, 2003) are closely related to $C$. sinensis and also cause serious biliary complications. Moreover, Opisthorchis spp. and Clonorchis are considered oncogenic as causing cholangiocarcinoma in about $10 \%$ of cases where millions are infected in Southeast Asia, Europe and Saudi Arabia (El-Sayed et al, 2019). also, microorganisms caused calcular obstruction must be considered (Yu et al, 2012).

\section{Conclusion}

Disorders of biliary tract affect a significant portion of the worldwide population, and the overwhelming majority of cases are attributable to cholelithiasis (gallstones).

IOUS is an accurate alternative to IOC in laparoscopic cholecystectomy with comparable sensitivity and specificity in CBD stones detection. It takes less time; guards against vascular anomaly related in-juries and easily done by trained surgeon. Intraoperative laparoscopic ultrasound is repeatable, safer, faster and less invasive than intraoperative cholangiogram. With adequately trained surgeons, it has a comparable sensitivity $\&$ specificity to IOC as a diagnosis for choldocolithiasis with ability to detect vascular and/or anatomical variations by Doppler.

\section{References}

Abdel-Rahim, AY, 2001: Parasitic infections and hepatic neoplasia. Dig. Dis. 19, 4:288-91.

Amott, D, Webb, A, Tulloh, B, 2005: Prospective comparison of routine and selective operative cholangiography. ANZ J. Surg. 75:378-82.

Benias, PC, Weine, DM, Jacobson, M, 2018: Diseases of the bile ducts. In: Handbook of Liver Disease. $4^{\text {th }}$ Ed. Elsevier

Birth, M, Ehlers, K, Delinikolas, K, Weiser, H, 1998: Prospective randomized comparison of laparoscopic ultrasonography using a flexible-tip ultrasound probe and intraoperative dynamic cholangiography during laparoscopic cholecystectomy. Surg. Endosc. 12, 1:30-6.

Catheline, J, Turner, R, Paries, J, 2002: Laparoscopic ultrasonography is a complement to cholangiography for the detection of choledo- 
cholithiasis at laparoscopic cholecystectomy. Br. J. Surg. 89, 10:1235-9.

Champault, G, Catheline, JM, Rizk, N, Boutelier, P, 1996: Apport de la laparoscopie \& de l' echo-laparoscopie dans le biland'extension des cancers du pancre'as (28 cases). Ann. Chir. 50: 875-85.

Cohen, S, Bacon, B, Berlin, J, et al, 2002: ERCP for diagnosis and therapy. Gastrointest. Endosc. 56: 803-9.

Copelan, A, Kapoor, BS, 2015: Choledocholithiasis: Diagnosis and Management. Tech. Vasc. Interv. Radiol. 18, 4:244-55.

Dili, A, Bertrand, C, 2017: Laparoscopic ultrasonography as an alternative to intraoperative cholangiography during laparoscopic cholecystectomy, World J. Gastroenterol. 23, 29:5450-4

Dyab, AK, El-Salahy, MM, Abdelmoneiem, H M, Amin, MM, Mohammed, MF, 2016: Parasitological studies on some intestinal parasites in primary school children in Aswan Governorate, Egypt. J. Egypt. Soc. Parasitol. 46, 3:581-6

El-Sayed, WMA, Abou-Bakr, AA, Morsy, TA, 2019: Oncogenic liver flukes acquired from eating raw or undercooked fish and crabs. J. Egypt. Soc. Parasitol. 49, 2:283-92

Falcone, R, Fegelman, E, Nussbaum, M, Brown, D, Bebbe, G, 1999: A prospective comparison of laparoscopic ultrasound vs. intraoperative cholangiogram during laparoscopic cholecystectomy. Surg. Endosc. 13, 8:784-8.

Flum, D, Flowers, C, Veenstra, D, 2003: A cost effectiveness analysis of intraoperative cholangiography in the prevention of bile duct injury during laparoscopic cholecystectomy. J. Am. Coll. Surg. 196, 3:385-93.

Haridy, FM, Ibrahim, BB, Morsy, TA, El-Sharkawy, IM, 1999: Fascioliasis an increasing zoonotic disease in Egypt. J. Egypt. Soc. Parasitol. 29, 1:35-48.

Koo, K, Traverso, L, 1996: Do preoperative indicators predict the presence of common bile duct stones during laparoscopic cholecystectomy? Am. J. Surg. 171:495-9.

Machi, J, Johnson, JO, Deziel, DJ, Soper, NJ, et al, 2009: Siperstein A. Routine use of laparoscopic ultrasound decreases bile duct injury: a multicenter study. Surg. Endosc. 23, 2:384-8.

Machi, J, Oishi, A, Tajiri, A, Murayama, K, Furumoto, N, et al, 2007: Routine laparoscopic ultrasound can significantly reduce the need for selective intraoperative cholangiography during cholecystectomy. 21, 2:270-4.

Massoud, AM, Morsy, TA, Haridy, FM, 2003: Treatment of Egyptian dicrocoeliasis in man and animals with Mirazid. J. Egypt. Soc. Parasitol. 33, 2:437-42.

Morsy, AT, Al-Mathal, EM, 2011: Clonorchis sinensis a new report in Egyptian employees returning back from Saudi Arabia. J. Egypt. Soc. Parasitol. 41, 1:21-5

Ney, M, Maluf-Filho, F, Sakai, P, et al, 2005: Echoendoscopy versus endoscopic retrograde cholangiography for the diagnosis of choledocholithiasis: the influence of the size of the stone and diameter of the common bile duct. Arch. Gastroenterol. 42: 239-43.

Perry, K, Myers, J, Deiziel, D, 2010: Laparoscopic Ultrasound as the primary method for bile duct imaging during cholecystectomy. Surg. Endosc. 10:208-213.

Robertson, G, Jagger, C, Johnson, P, 1996: Selection criteria for preoperative endoscopic retrograde cholangiopancreatography in the laparoscopic era. Arch. Surg. 131:89-94.

Siperstein, A, Pearl, J, Macho, J, Hansen, P, Gitomirsky, A, et al, 1999: Comparison of laparoscopic ultrasonography and fluorocholangiography in 300 patients undergoing laparoscopic cholecystectomy. Surg. Endosc. 13, 2:113-7.

Tazuma, S, 2006: Epidemiology, pathogenesis, and classification of biliary stones (common bile duct and intrahepatic). Best Pract. Res. Clin. Gastroenterol. 20, 6:1075-83.

Terpstra, O, 1996: Laparoscopic cholecystectomy: The other side of the coin. BMJ 312:13758.

Thompson, D, Arregui, M, Tetik, C, Madden, M, Wegener, M, 1998: A comparison of laparoscopic ultrasound with digital fluorocholangiography for detecting choledocholithiasis during laparoscopic cholecystectomy. Surg. Endosc. 12, 7:929-32.

Tranter, S, Thompson, M, 2003: A prospective single-blinded controlled study comparing laparoscopic ultrasound of the common bile duct with operative cholangiography. Surg. Endosc. 17, 2:216-9.

Yu, H, Guo, Z, Xing, W, Guo, X, et al, 2012: Bile culture and susceptibility testing of malignant biliary obstruction via PTBD. Cardiovasc. Intervent. Radiol. 35, 5:1136-44. 